\title{
Contributions to the Systematics of New World Macro-Moths
}

\author{
B. Christian Schmidt', J. Donald Lafontaine ${ }^{2}$
}

I Canadian Food Inspection Agency, Canadian National Collection of Insects, Arachnids and Nematodes, K.W. Neatby Bldg., 960 Carling Ave., Ottawa, ON, Canada K1A 0C6 2 Canadian National Collection of Insects, Arachnids, and Nematodes, Biodiversity Program, Agriculture and Agri-Food Canada, KW Neatby Bldg., C.E.F., Ottawa, Ontario, Canada K1A OC6

Corresponding authors: B. Christian Schmidt (Chris.Schmidt@inspection.gc.ca), J. Donald Lafontaine (LafontaineD@agr.gc.ca)

Received 2 April 2009 | Accepted 26 April 2009 | Published 12 May 2009

Citation: Schmidt BC, Lafontaine JD (2009) Contributions to the Systematics of New World Macro-Moths. In: Schmidt BC, Lafontaine JD (Eds) Contributions to the Systematics of New World Macro-Moths. ZooKeys 9: 1-2. doi: 10.3897 /zookeys.9.183

This issue of ZooKeys marks the first of several planned volumes entitled "Contributions to the Systematics of New World Macro-Moths," initiated as a compilation of alpha-taxonomic based projects on the New World macro-moths. The focus of this series will be the North American noctuoid and geometrid fauna, although several additional manuscripts on the Neotropical fauna are already in preparation for future volumes. The North American macro-moth fauna is typically thought of as being relatively wellknown, but our taxonomic knowledge base is far from complete - we are aware of over 200 unrecognized North American species of Noctuoidea, with similar numbers for the Geometridae, to say nothing of the Central and South American fauna. Many new species and taxonomic problems have been highlighted by the advent of molecular 'barcoding' (Ratnasingham and Hebert 2007), particularly cryptic species (i.e. species that have not been recognized as distinct due to similarity with another species); however, three other sources continue to be significant reservoirs of unnamed species: new species never collected before; species long recognized as distinct (in some cases over 50 years!), but without an available name; and dissection of genitalia in poorly studied genera that reveal species complexes. It is our hope that this series will not only fill in some of these knowledge gaps, but encourage further research on baseline taxonomy at a time when it is so desperately needed.

Copyright B. Christian Schmidt,J. Donald Lafontaine. This is an open access article distributed under the terms of the Creative Commons Attribution License, which permits unrestricted use, distribution, and reproduction in any medium, provided the original author and source are credited. 
Since the publication of the last check list of North American Noctuoidea over 25 years ago (Hodges et al. 1983), the family-group systematics of the Noctuoidea has changed dramatically. In addition, over 500 noctuoid species have been added to the North American fauna: 320 described as new species, 124 as new records (mostly from Arizona, Texas and Florida), and 56 as taxonomic splits resulting in subspecies or synonyms being given species status. A revised catalogue of North American Noctuoidea is forthcoming in the next volume of "Contributions to the Systematics of New World Macro-Moths," planned for the winter of 2009/10; the content of the current volume has accordingly focused on the Noctuidae so that the species names described herein be available for this check list. However, expansion of coverage to other groups, particularly Geometridae, is planned for future volumes, and interested authors are encouraged to contribute. Already, this collaborative effort of both amateur and professional lepidopterists and taxonomists has brought together a significant contribution to noctuid taxonomy within a relatively short time frame, as a result of contributions from 16 authors, editors and/or reviewers. Eighteen new species and one new genus are described herein, and we hope subsequent volumes will elicit equally positive responses. Prospective authors are encouraged to contact the section editors.

\section{References}

Hodges RW, Dominick T, Davis DR, Ferguson DC, Franclemont JG, Munroe EG, Powell J (1983) Check List of the Lepidoptera of America North of Mexico. EW Classey Ltd and the Wedge Entomological Research Foundation, Washington, D.C., USA.

Ratnasingham S, Hebert PDN (2007) BOLD: The barcode of life data system. Molecular Ecological Notes 7: 355-364. 